Journal Home Page:

http://perlinguam.journals.ac.za

\section{Per Linguam} A Journal for Language Learning
Tydskrif vir Taalaanleer

\title{
RECOGNISING SPEECH ACTS
}

Phyllis Kaburise

University of Venda

\begin{abstract}
Speech Act Theory (SAT), a theory in pragmatics, is an attempt to describe what happens during linguistic interactions. Inherent within SAT is the idea that language forms and intentions are relatively formulaic and that there is a direct correspondence between sentence forms (for example, in terms of structure and lexicon) and the function or meaning of an utterance. The contention offered in this paper is that when such a correspondence does not exist, as in indirect speech utterances, this creates challenges for English second language speakers and may result in miscommunication. This arises because indirect speech acts allow speakers to employ various pragmatic devices such as inference, implicature, presuppositions and context clues to transmit their messages. Such devices, operating within the non-literal level of language competence, may pose challenges for ESL learners.
\end{abstract}

\section{Key words}

pragmatics, speech act theory, direct and indirect speech acts, implicature, inference and context

\section{INTRODUCTION}

Meaning is created when speakers' intentions are communicated to hearers, in other words, when a speaker's speech act or speech function is accurately interpreted by a hearer. According to pragmaticians, this is possible because speech acts have standardised structural forms which are assigned to standardised language functions. These characteristics assist interlocutors to create meaning as it becomes possible to assign speech forms to speech functions. This has also led to the acceptance that there is a correlation between the form and function of speech acts. Austin (2005) asserted that the three major sentences types/forms in English, namely, the imperative, the interrogative and the declarative, have the functions of ordering, requesting and stating, respectively. However, experience has shown that the fit of form and function does not always occur in linguistic behaviour. For example, the structural form of an imperative is hardly used; rather, other forms like suggestions, statements and requests are the preferred mode of 'ordering' an action. Hence, a command for the dishes to be washed can be framed in various ways:

1. It is 8:00 and the dishes are still dirty.

2. There isn't a single clean dish in this house.

3. Isn't 8:00 the time when the kitchen is cleaned in this house?

4. You know the problem we have with ants; maybe you could do the dishes now?

5. Oh my goodness, what an untidy kitchen!

6. Wash the dishes. 
7. I really would like a clean kitchen.

Of the statements given above, only number 6 is structured as a command; the other six have been expressed using various speech acts and forms, such as requests, suggestions and statements. When there is a lack of correlation between the form and the function, yet meaning is created, Austin (2005) named these indirect speech acts. Austin acknowledged that indirect speech acts increase the chances of misunderstanding during a speech event, but went on to say that other conditions or clues which are present during a speech event further assist interlocutors to reduce the dangers of miscommunication. For native speakers of a language, usually, the dangers of miscommunication due to exploiting indirect speech strategies is minimal, but for second language speakers, there is a real danger of lack of understanding between interlocutors. Inability to grasp the full intent of an utterance within academic contexts has far-reaching implications.

\section{Background to the problem}

The fact that a connection exists between language, cognitive development and academic performance is well documented (Stephen, Wellman \& Jordaan, 2004) and this has considerable significance for learners whose medium of instruction is a second, or worse still, a foreign language. Moving up the academic ladder, even at pre-university stage, presents challenges for learners and even more for multilingual learners with minimum opportunity to interact socially, economically and culturally in the language of instruction. In such a context, the language in the classroom remains a foreign one, and at every opportunity, the learners revert to the comfort zone of their mother tongue. This is a situation which is seen in rural, under-resourced schools, among first-generation scholars, and in low socio-economic communities (Kaburise,2012 (b). Such communities, as seen in some parts of Venda in the northern part of the Limpopo province, tend not to have a facilitating environment for the learning of other languages, such as English. English is limited to the English period in school and there is no re-enforcement from either the other subject teachers or the home or the community.

English competence of learners in these schools tends to be at the literal or survival levels and to exhibit mainly 'organisational knowledge' (Bachman \& Palmer, 1996, Kaburise, 2012(a)). A literal level of language competence ensures survival in the language arena; it allows users to perform basic language functions, show some fluency, and pay attention to grammatical structures, without manipulating the language, to achieve a multiplicity of language goals or to enhance everyday language events. In other words, learners at this level show limited manipulation of pragmatic strategies.

Learners at this level of proficiency also tend to use more direct forms of speech acts, for example, using a declarative to make a statement, using an interrogative to ask questions and issuing a direct command if they want something done. However, utterances from users of language with pragmatic competence show a mixture of direct and indirect speech acts, a language behaviour which shows high levels of versatility and command of the language. Learners' desire for the safer option of direct speech acts is quite understandable as the use of indirect speech acts is the usual source of miscommunication or misunderstanding for some ESL learners as they are unable to recognise the intentions or meanings of such utterances. Pragmatically competent speakers of a language have the ability to use indirect speech acts such as poetic turn of phrases, innuendoes, satire, sarcasm, irony and others to enhance their 
verbal interactions. This is seen as moving from a literal survival level to a more critical, advanced control of language or moving from utilisation of direct speech acts to indirect ones.

\section{Statement of the problem}

The sign of a proficient user of a language is the person's ability to control, or as Austin puts it in the title of his book, '---- do (things) with words' $(1962,2005)$. To communicate, basically, means a speaker getting a message across to a hearer. However, different ways to achieve this exist, just as there are different ways of getting from one destination to another or different items can be classified as clothes or food. For learners in Grade 12 who are potential candidates for tertiary studies, a certain threshold of linguistic success is required, an aspect of which is demonstrated by pragmatic competence in the use of language or the upgrading of literal to critical language use. Learners in most rural schools around Venda show a belowaverage versatility in the command of pragmatic manipulation of language usage routines (Kaburise, 2011(a)). This of course has a tremendous negative impact on their academic success as numerous researchers have shown the link between critical literacy and language success (Elder, 2007; Rashid \& Hashim, 2008).

\section{Hypothesis}

The project described in this article was based on the hypothesis that ESL learners have difficulty interpreting indirect speech acts because of the divergence between sentence and utterance meaning and that this has a negative impact on their pragmatic use of language.

\section{Objective}

The target group for the project was a group of Grade 12 learners from a rural area in Limpopo. The objective was to ascertain whether these learners have the ability to recognise direct and indirect speech acts in linguistic events such as suggestions, commands, apologies and requests and to see whether the tension between the form and function of speech acts affects the interpretation of these acts.

\section{Theoretical framework}

Speech act theory is partly taxonomic and partly explanatory as it is not only an attempt to break down, scientifically and philosophically, the procedures involved in making an utterance but is also an attempt to classify systematically the reasons for the linguistic acts we make. Both Austin $(1962,2005)$ and Searle (1969) based their theories on the hypothesis that 'speaking a language is engaging in a rule-governed form of behaviour' (Searle 1969: 11), which results in the accomplishment of some specific social act, function or intention. These linguistic events or speech acts are classifiable, for example, as a promise, a request, an apology, a compliment or advice, and these functions have sentence forms which go with them.

A number of theorists have attempted to categorise speech functions. Of particular interest to this paper is the classification of Searle (1969) a student of Austin. Searle (1979: 27) was unimpressed with Austin's classification on a number of points, and these perceived shortcomings culminated in Searle's article, A Classification of Illocutionary Acts, in which 
he offers his own classification, 'a reasoned classification of illocutionary acts into certain basic categories or types'

Searle's speech act categories are as follow:

Representatives: These are assertions which represent the state of affairs, or as Mey (1993: 31) claimed, they represent 'reality'. They are seen, for example, in assertions, statements, claims and suggestions. They can be proved as either true or false. For example,

8. I live in Sibasa in the Northern Province. (The simple present tense is used more often than the present perfect tense).

Commissives: These acts commit the speaker to some particular future course of action. They may be in the form of promises, offers, threats or vows. Their use may be seen in statements such as,

9. Touch the dial one more time and you will regret it.

10. If it is a fine day tomorrow we will go to the Plaza.

Directives: These speech acts are intended to get the hearer to carry out an action. These include commands, requests, invitations, dares, or challenges, as in the following:

11. Please join us for dinner on Friday.

12. Do not barge into my room.

Expressives: These are speech acts which indicate the speaker's psychological state of mind or attitude to some prior action or state of affairs. They are seen in greetings, apologies, congratulations, condolences and expressions of giving thanks. The following sentences are some examples:

13. Wow! That was a brilliant speech.

14. Oh dear, I am so sorry about the incident.

Declaratives or Performatives: These utterances are those which bring about the state of affairs that they name. Declaratives are typically broadcast within a social group and rely for their success on a speaker being sanctioned by the community, institution, committee, or even a single person in the group, to perform such acts under specialised conditions, as in,

15. You are hired!

16. May the Lord richly bless you and your family.

In statements 15 and 16, the intentions or the functions -- of being hired and being blessed -can be said to have taken place the same time that the speaker was uttering those words. Utterances of the type in 8-16 are classified as direct speech acts.

An indirect speech act is defined as a speech act where the sentence form/meaning does not correspond to the speech function, in other words, a situation where there is tension between the form and function of an utterance, as in the following examples:

17. The money I lent to you would come in handy now as I need to get some items from the shops.

18. My garden has got the biggest and healthiest weeds that I have seen in a long time and I would like something done about them. 
Sentence 17 is a demand for the return of the money and 18 is a complaint and command, yet both are framed in the form of information-giving declarative statements. An observation of people's communication behaviour shows that most speech acts are of the indirect type; therefore, they present a challenge to Austin's (1962) form and function aspect of speech acts. On the face of it, what speakers do with their utterances seems quite unrestricted by the literal surface form (sentence type). Therefore, speaker's meaning may be underdetermined by the physical structure of the utterance; words and expressions may have a literal or a non-literal meaning, and a fair amount of the speaker's intention is implied rather than being categorically stated. This is because not all speech functions are represented by specific sentence forms but may be represented by several sentence forms, with the exception of the strictly formularised sentence forms of the performatives.

In exchange 19 below, Speaker B has correctly interpreted A's utterance as a request for academic assistance, indirectly stated as an assertion, and has responded in a similar vein by expressing a negative intention, using a positive utterance.

19. Speaker A (whispering): My answer to question $C$ looks odd. Speaker B (also whispering): This is an examination room!

This example suggests that performing a speech act is a matter of having a certain communicative intention in uttering certain words. Searle (1979(b): 77) classifies this as using indirect speech acts, and this type of language usage prompted him to distinguish 'speaker meaning' or 'utterance meaning' from 'sentence meaning' as explanations of indirect speech acts. The position Searle takes here is that utterance codes or form may have meanings which differ from that of the speaker's meaning in indirect speech acts, as is also shown by sentences 20 and 21 .

20. Your room is a pigsty.

21. Sam is such a lamb; I really like him.

If a speaker utters an indirect speech act, such as in 20 and 21, then it may have an ironic, sarcastic or metaphoric usage, which the speaker intends it to have. Therefore, sentences are said to have both a semantic representation (literal sentence meaning) and a communicative pragmatic function (utterance or speaker meaning).

Articulating the differences between literal sentence meaning and pragmatic utterance meaning is usually attributed to Grice (1971), who differentiated between the semantic meaning of a sentence, as the basic, ordinary and conventional, and the more unorthodox, implied and creative meaning as belonging to the domain of pragmatics. Semantic or sentence meaning is derived from the composite meaning of the constituents of that particular sentence. Such sentences are usually not likely to be misunderstood as long as the hearer and speaker are familiar with the semantic properties of the individual words. Words taken at their literal values have an abstract slant and are more in line with the formalist approach to meaning.

Grice (1971) described indirect, pragmatic or utterance meaning as usage-oriented, not fixed but governed by the intentions of the speaker on any particular occasion. Meaning is not permanently encoded in words or expressions but is negotiated by the interlocutors at any given time; hence, sentence meaning may differ from speaker meaning. Speaker meaning can be seen to be socially controlled, context bound and open to speaker creativity; meaning is not in the surface structures and words but is created beyond these factors. Speaker meaning need 
not be code-related but may be inferred through a process quite different to meaningrealisation based on the recognised semantic properties of sentences. This difference is referred to by different terms, such as, sense (sentence meaning) and force (utterance/speaker meaning) or properties of grammar and principles of conversation.

Non-literal interpretation of utterances or indirect speech acts, naturally, can create challenges for hearers as they grapple with idiosyncratic speaker utterances. Interpreting speaker intention on such occasions requires more than mere decoding of constituents of sentences, and Grice (1971) suggested that the extra level of meaning is deduced using the twin notions of inference and implication. Speakers imply and hearers infer certain meanings from utterances based on their shared background and the immediate context of the utterance.

Context operates at two levels: external and internal settings. Internal is the more visible and commonly accepted notion of context, which includes the relationship between the constituents of the sentence codes as well as other content particulars. External context here is detailed as the pragmatic presuppositions or inferences about the beliefs, knowledge and experiences of the participants required to understand an utterance. These levels of context are based on the notion that a structural-linguistic context provides an insufficient account of the factors involved in meaning creation, thereby justifying a consideration of extra-linguistic factors. Grice (1957), similarly, talks of the assumptions which ensure co-operation between conversation partners.

Context can be described as the presuppositions or variables that are linguistically relevant in the creation of discourse. The hypothesis is that most utterances can be understood in diverse ways, based on the configuration of the context, and people's interpretation of an exchange is directly related to the prominence of one or more of these variables: lexical, syntactic, environmental, social and stylistic decisions. Context then is a frame or schema through which utterances are examined and interpreted. Schemata are considered to be conventional knowledge: those structures which exist in our memory and are activated under certain conditions in the interpretation of what we experience. At the very obvious level, we have schemata for the usual verbal activities in our lives, for instance, food schemata, family schemata, office schemata, and so on.

For instance, the utterance, 'These are lovely cakes' has possible meanings depending on context variables such as the location, the role players, its phonological characteristics, the time of day, as well as the accompanying linguistic and non-linguistic marks. These conditions or variables can be referred to as an 'organising principle' in meaning interpretation, as they determine and channel inferences which either foreground or underplay aspects of the background and, hence, the meaning of an utterance.

\section{Methodology}

The participant group was comprised of 60 female and 40 male Grade 12 ESL learners with ages ranging from 16 to 20 years. The area where the school is situated is classified as 'rural'. The participants were presented with four situations/contexts requiring a speaker to make a suggestion, an apology, or a request, or to issue a command. Each context was followed by five appropriate responses, which ranged in levels of directness. Respondents were required to indicate, on a scale of 1-3, which responses were appropriate to the given scenario/context. A score of 3 indicates the most appropriate response. In discussing the choices made, this report 
examines respondents handling of pragmatic aspects like, indirect speech acts, the distinction between sentence and utterance meaning, and the role of inferences and implicatures as well as context or presuppositions in creating meaning.

Grade 12 learners were selected as pragmatic competence is dependent on a combination of other language abilities such as those in syntax, phonology and semantics, abilities which can be presumed to exist in Grade 12 learners. In addition, the English language teacher in Grade 12 has an Honours degree in English language teaching and pragmatics and speech act theory were some aspects of the programme's curriculum. An assumption can therefore be made that pragmatic principles should have influenced this teacher's instruction in the class.

A questionnaire was given to learners during a normal class period. Before handing out the questionnaire, the class teacher explained its purpose and the learners indicated their wiliness to participate in the study. The learners were not required to indicate their names, school or teacher. They were, however, required to provide their ages as an indication of the length of their exposure to English, although age was not a variable in the interpretation of the results.

\section{Part 2: DISCUSSION OF THE QUESTIONNAIRE AND RESPONSES}

\section{1}

A friend you had invited to your party did not make it. The next day you met him/her. Which of the following statement/s would you consider an appropriate statement for him/her to make?

1. I am sure you had a lovely time.

2. I am kicking myself.

3. My brother did not come with his car this weekend.

4. I am sorry I couldn't make it to your party.

5. It was raining so hard yesterday afternoon.

- Statement 4 is the direct speech act of apologising with the appropriate terminology.

- In statements 1, 2, 3, and 5 various forms of indirectness have been used to indicate to the hearer that the speaker is contrite about missing the party.

- In 1 and 2, the speaker has used a compliment, probably with a wistful attitude, to indirectly tell the hearer that he/she regrets missing the occasion which must have lived up to expectations. Here we have a divergence between sentence meaning and utterance meaning.

- In 3 and 5, the speaker has described situations which he/she felt were sufficient justification for the non-attendance. The speaker assumes that, although an apology has not directly been offered, the hearer will infer this speech act. Similar to statements 1 and 2, the hearer will need to infer that the statements are apologies.

\section{Responses}

\begin{tabular}{|l|l|l|l|l|l|}
\hline Appropriateness & Statements & \multicolumn{6}{l|}{ and Responses in Percentage } \\
\hline & $\mathbf{1}$ & $\mathbf{2}$ & $\mathbf{3}$ & $\mathbf{4}$ & $\mathbf{5}$ \\
\hline & & & & & \\
\hline Most & 2 & 2 & 9 & 71 & 16 \\
\hline Some & 14 & 7 & 22 & 16 & 41 \\
\hline Least & 16 & 16 & 41 & 4 & 23 \\
\hline TOTAL & 32 & 25 & 72 & 91 & 80 \\
\hline
\end{tabular}

Per Linguam 2012 28(1):36-48 
The responses indicate that answer 4 (I am sorry I couldn't make it to your party) was considered most appropriate by $71 \%$ of respondents. Statement 5 (It was raining so hard yesterday) was considered as having some appropriateness by $41 \%$, while statement 3 (My brother did not come with his car this weekend) was identified by $41 \%$ as the least appropriate of the three.

As indicated in the discussion, 4 has the structural form of an apology, hence the response is not surprising. Statements 3 (My brother did not come with his car this weekend) and 5 (It was raining so hard yesterday), although explanations and not direct apologies are usual mitigating reasons that can be offered to support implicit or implicit apologies. Hence, the appropriateness of 3 and 5 is not difficult to establish. It is therefore not surprising that students selected these responses despite the form not matching the function.

In Statement 1 (I am sure you had a lovely time), a compliment is being used as an apology and, by implication, the hearer will deduce that the speaker regrets missing such a lovely event. In 2 (I am kicking myself), an idiomatic expression may have been too colloquial for the caliber of the respondents. Statements 1 and 2 are the most indirect of the responses, in that the sentence meanings do not correspond with the utterance meanings; therefore, the very low selection rate for them is not surprising.

This argument is also reflected in a comparison of the total preference rate for the statements. In order of preference, are statements, 4, 5, 3, 1 and 2, with corresponding percentage response rates of $\mathbf{9 1 ,} \mathbf{8 0}, \mathbf{7 2}, \mathbf{3 2}$, and $\mathbf{2 5}$, respectively.

This shows that the most direct form, 4 (I am sorry, I could not make it to your party) is the most preferred response and the most indirect, 2 (I am kicking myself) is the least preferred form. In other words, statement 4 , where the sentence meaning corresponds to the utterance meaning and where the form and the function match is preferred by respondents.

\section{2}

You were playing very loud music when your parents came home. Which of the following statement/s would you consider an appropriate statement for them to make?

6. The baby is sleeping.

7. I can't hear myself think here.

8. Turn the noise down.

9. Our neighbours are just coming in.

10. Tomorrow is the due date for my report for the office.

- In statements 6, 7, 9 and 10, the speaker has used an indirect speech act, that is, a statement, to issue a command.

- In 6, 7, 9 and 10, the speaker has described world situations (sleeping baby, respect for neighbours and writing of reports) which require low volumes of noise. By implication, the hearer should realise that the speaker is demanding less noise.

- In 8, the imperative has been used to command the hearer to reduce the volume; therefore, the statement is a direct speech act as the form corresponds to the function. 
Responses

\begin{tabular}{|l|l|l|l|l|l|}
\hline Appropriateness & Statements & \multicolumn{2}{l|}{ and Responses in Percentage } & \\
\hline & $\mathbf{6}$ & $\mathbf{7}$ & $\mathbf{8}$ & $\mathbf{9}$ & $\mathbf{1 0}$ \\
\hline & & & & & \\
\hline Most & 13 & 6 & 67 & 10 & 4 \\
\hline Some & 48 & 15 & 10 & 11 & 16 \\
\hline Least & 14 & 25 & 16 & 35 & 10 \\
\hline TOTAL & 75 & 46 & 93 & 56 & 30 \\
\hline
\end{tabular}

The responses indicate that statement 8 (Turn the noise down.) was considered by $67 \%$ of respondents as the most appropriate; $48 \%$ of respondents thought statement 6 (The baby is sleeping) had some appropriateness; while 35\% of respondents thought statement 9 (Our neighbours are just coming in) to be the least appropriate of the three. Statement 8 is the most direct of the utterances; therefore, its selection by the majority of respondents as the most appropriate is not surprising.

Utterances 7 (I can't hear myself think in here) and 10 (Tomorrow is the due date for my report to the office) attracted fewer respondents than the three above. Respondents not seeing the relevance of 7 is understandable as it is an idiomatic expression and hence the most indirect of all the statements. In fact, I would have expected statement 7 to have the lowest selection rate as the sentence meaning is most divergent from utterance meaning. The low selection rate for 10 is rather surprising as I would have expected less difference between selection rates for statements 9 and 10. In terms of indirectness, they are similar and the only reason I can offer is that the respondents can identify more with the idea or context of a loud noise disturbing a neighbour than with their parents writing reports for offices. It can be said therefore that the respondents incorporated additional context variables in selecting statement 9 over 10. This further supports the argument of this paper that indirect speech acts which require extensive contextual clues pose difficulties for ESL speakers.

The discussion above is supported by the total response rate for all the statements. The order of preference is $8,6,9,7$ and 10 , reflected by a percentage response rate of $93,75,56,46$ and 30, respectively. Therefore 8 , the most direct of the speech acts is the most preferred and 10 , which required external context clues, inference and an amount of world knowledge, attracted the fewest respondents.

\section{3}

You urgently need money. Unfortunately your parents are not around so you need to ask a family friend for the money. Which of the following statement/s would you consider appropriate to make?

11. Can you lend me some money until Friday when my parents come back?

12. I was not able to pay for my registration and Friday is the last day.

13. Can you lend me some money?

14. I urgently need some money.

15. Things are so expensive these days.

- In statements 12 and 15 , we see examples of indirect requests, where the speaker makes no mention, even obliquely, of money. These statements require the hearer to make inferences at quite a sophisticated level to understand the intention of the speaker. 
- In 12 , the hearer has to rely on specialised world knowledge about the implications of missing deadlines to understand the urgency of the request.

- Although 11 and 13 are both the usual form of performing the speech act of requesting, that is the use of the interrogative, 11 also contains a 'face saving' phrase to justify the speaker's need for money.

- In 14, there is also some face saving for the speaker as an implicit request has not been articulated, and this same statement can be uttered in other less face-losing contexts, for example, by someone who needs to withdraw money from an ATM or a bank. Statement14 is also 'face saving' for a speaker since a refusal to such a request is usually not direct. A hearer presented with utterance 14 and who is unable to honour the request would usually offer explanations or use implicature to avoid directly refusing a request which has not been directly or implicitly articulated.

- Utterance 15 is an example of an indirect speech act where a declarative statement or an observation needs to be interpreted as a request. Usually, 15 could be a preamble to the main sentence which may go like - therefore I wasn't able to buy enough grocery, can you lend me some money until my parents come back next week?

Responses

\begin{tabular}{|l|l|l|l|l|l|}
\hline Appropriateness & Statements and Responses in Percentage & \multicolumn{1}{l|}{} \\
\hline & $\mathbf{1 1}$ & $\mathbf{1 2}$ & $\mathbf{1 3}$ & $\mathbf{1 4}$ & $\mathbf{1 5}$ \\
\hline & & & & & \\
\hline Most & 46 & 17 & 20 & 13 & 4 \\
\hline Some & 28 & 19 & 31 & 16 & 6 \\
\hline Least & 14 & 19 & 24 & 28 & 19 \\
\hline TOTAL & 89 & 55 & 76 & 55 & 29 \\
\hline
\end{tabular}

Statement 11 (Can you lend me some money until Friday when my parents come back?) was identified as the most appropriate by $46 \%$ of respondents. Statement 13 (Can you lend me some money?) was considered as having some appropriateness by $31 \%$ of respondents. Statement 14 (I urgently need some money) was seen as the least appropriate among the three statements by $28 \%$ of the respondents. Statement 12 (I was not able to pay for my registration and Friday is the last day) and Statement 15 (Things are so expensive these days) were not seen to be as relevant as the three above. Statement 15 may not have been so popular because it is the most indirect of the five and may have sounded too oblique and circuitous.

The total figures further support the conclusions drawn as the order of preference was, 11, 13, $12 \& 14$ and 15 , with a response rate of $89 \%, 76 \%, 55 \%$ and $29 \%$, respectively, although I consider some of these results not entirely conclusive. For example, the high response rate for 11 and 13 is understandable - they both have the interrogative forms for requests with additional appropriate lexical items. However, I would have expected more or less similar response rates for 12 and 15 as both require implicature, with 12 requiring extra world knowledge. I presume 12 'sounds' more of a request than does 15 , which has the appearance of just an information-giving declarative. Similarly, why the difference between the response rates for 13 and 14 is so high is not clear as the two statements have identical sentence meanings. Despite this inconclusiveness, it is possible to say that 11 and 13, those statements framed as interrogatives, have been identified by most as requests, demonstrating respondents' preference to match form and function. 


\section{4}

A friend has on an outfit which you feel is absolutely unsuitable for her and the occasion. Which of the following statement/s would you consider appropriate to make?

16. Don't you have another outfit?

17. I really like the other outfit I saw you wearing last week.

18. The invitation says we must dress formally.

19. I don't think it is a good idea to be so different from the others.

20. I saw this outfit in the shop but I did not buy it.

- Statements 16-20 require more discernment from the hearer; this is because although all the utterances are suggestions, the only distinguishing feature among them is the level of politeness inherent in each utterance.

- The para-linguistic features employed in uttering 16 could make it either an uncomplimentary remark or a well-meaning suggestion or advice showing that there could be extreme divergence between sentence and utterance meaning.

- The compliment-style of 17 , the implication that the hearer may have misread the invitation in 18 , and the well-meaning caution of statement 19 mean that the impact of the unpalatable sentiment in these statements is reduced.

- In 20, the existence of possible reasons for the speaker not buying a similar outfit creates some ambivalence, allowing the hearer to come to multiple interpretations of the utterance and hence may reduce any perceived 'impoliteness' of the statement.

\section{Responses}

\begin{tabular}{|l|l|l|l|l|l|}
\hline Appropriateness & Statements & \multicolumn{2}{l|}{ and Responses in Percentage } \\
\hline & $\mathbf{1 6}$ & $\mathbf{1 7}$ & $\mathbf{1 8}$ & $\mathbf{1 9}$ & $\mathbf{2 0}$ \\
\hline & & & & & \\
\hline Most & 17 & 51 & 12 & 14 & 6 \\
\hline Some & 11 & 14 & 43 & 24 & 8 \\
\hline Least & 25 & 13 & 14 & 27 & 21 \\
\hline TOTAL & 53 & 78 & 69 & 65 & 35 \\
\hline
\end{tabular}

Statement 17 (I really like the other outfit I saw you wearing last week) was considered by $51 \%$ of respondents as the most appropriate way to frame a suggestion in this context. Statement 18 (The invitation says we must dress formally) was seen as having some appropriateness by $43 \%$ and 19 (I don't think it is a good idea to be so different from the others) as the least appropriate among the three by $27 \%$ of respondents. These results are not surprising as these three statements sound quite polite.

As mentioned earlier, 16 (Don't you have another outfit?) is open to multiple interpretation -an uncomplimentary remark framed as a question or a well-meaning genuine concern about the outfit. Similarly, reasons for the non-buying of the outfit, statement 20, can be multiple no money, right size not available, no time, right colour not available, and so on -- and this might result in an incorrect sentence meaning and hence the hearer missing the utterance meaning as well.

The total response rates are in line with the earlier discussions as the order of preference is $\mathbf{1 7}$, $18,19,16$ and 20 , with response rates of $78 \%, 69 \%, 65 \%, 53 \%$ and $35 \%$, respectively. 


\section{CONCLUSION}

These results show that respondents are conversant with the speech acts of apology, command, request and suggestion, particularly when expressed as direct speech acts. However, statements which are dependent on context clues and world knowledge and where there is divergence between sentence and utterance meaning posed some problems for respondents. In other words, indirect speech acts in which the function is implicitly stated or hearers have to rely on implicatures, inferences and presuppositions to obtain the utterance meaning, and hence the form did not correspond to the function, were not as easily recognised by respondents. Indirectness arising from the statement being an idiom also did not have a high rate of recognition.

\section{REFERENCES}

AUSTIN, J. 1962. How to do things with words. ( $1^{\text {st }}$ edition) Oxford, UK: Oxford University Press.

AUSTIN, J. 2005. How to do things with words. ( $2^{\text {nd }}$ ed.) Oxford, UK: Oxford University Press.

BACHMAN, L \& PALMER, A. 1996. Language testing in practice: designing and developing useful language tests. Oxford (OUP)

ELDER, C. 2007. Enhancing chances of academic success amongst first year undergraduates from diverse language backgrounds. Paper presented at EALTA conference, Spain.

GRICE, P. 1957. 1957. Meaning. Philosophical Review 66

GRICE, P. 1969. Utterer's meaning and intention. Philosophical Review, 78:147-177.

GRICE , P. 1971. Meaning. In Steinberg and Jokobovits (eds) Semantics: An interdisciplinary reader in philosophy, linguistics and psychology. Cambridge: Cambridge University Press.

HERSKOVITS, A. (2008). Context and language. Accessed at http://boggie.cs.unitn.it/eecs97/Discussion/Archives/0010.html

KABURISE, P, 2007. Conversation principles and second language utterances. Per Linguam

KABURISE, P. 2012(a). Linguistic meaning - creating strategies of potential Univen students: implications for access and success (in print)

KABURISE, P. 2012(b), Academic and socio-economic variables in tertiary success (in print)

MEY, J. 1993. Pragmatics: an introduction. Oxford, Blackwell.

RASHID , RA., \& HASHIM, RA.,2008. The relationship between critical thinking and language proficiency of Malaysian undergraduates. EDU-COM International Conference.

SEARLE, J. 1965. What is a speech Act? In Searle, J. (Ed.) The philosophy of language Oxford, UK: Oxford University Press.

SEARLE, J. 1969. Speech Acts: An essay in the philosophy of language. Cambridge, Cambridge University Press.

SEARLE, J. 1979 (a). A classification of illocutionary acts. Language and Society 5. 
SEARLE, J. 1979 (b). Expressions and meaning: Studies in the Theory of Speech Acts. Oxford: oxford University Press.

STEPHEN, DF., WELLMAN, JC., JORDAAN, WJ. 2004. English language proficiency as an indicator of academic performance at a tertiary institution. SA Journal of Human Resource Management: vol 2 No. 3.

\section{BIOGRAPHICAL NOTE}

Phyllis Kaburise is in the language section of the English Department, University of Venda. Her research interests are in pragmatics and language literacy development. 